\title{
Lipogenesis from Lactate in Fetal Rat Brain during Late Gestation
}

\author{
JUAN P. BOLAÑOS AND JOSÉ M. MEDINA
}

Departamento de Bioquímica y Biología Molecular, Facultad de Farmacia, Universidad de Salamanca, Spain

\begin{abstract}
Much evidence suggests that lactate may play a relevant role as a metabolic substrate for the brain immediately after delivery. In this work, the rate of lactate, glucose, and 3-hydroxybutyrate incorporation into $\mathrm{CO}_{2}$, phospholipids, and sterols was studied in fetal rat brain slices during the last $3 \mathrm{~d}$ of gestation. Lactate was the best substrate for the brain during the late gestation, not only as a source of energy, but also as precursor of brain phospholipids and sterols. The rates of oxidation and lipogenesis from glucose and 3-hydroxybutyrate showed a progressive decrease during late gestation $(10-15 \%$ reduction on $\mathrm{d} 20.5, p<0.05$, and $22-33 \%$ on $\mathrm{d} 21.5, p<0.01$, for oxidation; 14-18\% on d 20.5, $p<0.05$, and $20-22 \%$ on $\mathrm{d} 21.5, p<0.05$, for lipogenesis), whereas lactate maintained its rate of utilization in the same circumstances. The main phospholipid synthesized throughout the late gestation was phosphatidylcholine. The synthesis of phosphatidylcholine and phosphatidylethanolamine from lactate, glucose, and 3-hydroxybutyrate decreased during late gestation. Under these circumstances, however, the rate of phosphatidylserine synthesis from glucose was unchanged; it decreased from 3-hydroxybutyrate and increased from lactate. The rate of desmosterol synthesis was about 3- to 4-fold higher than those of cholesterol and lanosterol. Our results suggest that the capacity of fetal brain for lactate utilization remains high during late gestation, but the capacities for the utilization of glucose and 3-hydroxybutyrate decrease until term. This may indicate that lactate is an important substrate for brain development during late gestation. (Pediatr Res 33: 66-71, 1993)
\end{abstract}

\section{Abbreviations}

PC, phosphatidylcholine

PE, phosphatidylethanolamine

PI, phosphatidylinositol

PS, phosphatidylserine

It is well established that ketone bodies (3-hydroxybutyrate and acetoacetate) are important substrates for the developing brain and that, together with glucose, they are able to meet most of the brain's metabolic requirements during the suckling period (1). However, just before the onset of lactation, i.e. during the presuckling period, there is a very low concentration of ketone bodies in rat blood (2). Moreover, the newborn rat shows a

Received June 24, 1992; accepted August 31, 1992.

Correspondence and reprint requests: Prof. José M. Medina, Departamento de Bioquímica y Biologia Molecular, Facultad de Farmacia, Aptdo. 449, E37080 Salamanca, Spain.

Supported in part by C.A.Y.C.I.T., Spain; F.I.S.S.S., Spain; and Fundación Ramón Areces, Spain. J.P.B. was a recipient of a fellowship from the Fondo de Investigaciones Sanitarias de la Seguridad Social, Ministerio de Sanidad y Consumo, Spain. profound hypoglycemia during the first postnatal hours $(2,3)$, and hence the supply of glucose is not enough to provide the brain's energy requirements. On the other hand, the large amounts of lactate accumulated in blood during late gestation are rapidly removed during early postnatal life (2-5). During the first $2 \mathrm{~h}$ of extrauterine life, most of this lactate is consumed through the tricarboxylic acid cycle (6), because gluconeogenesis is not still active during this period $(3,4)$. In fact, lactate is an excellent substrate for lipid synthesis in brain slices (7) or dissociated brain cells (8) in neonatal rats.

Because lactate is accumulated in fetal blood and is the main fuel available to fetal tissues during late gestation (9), we attempted to evaluate the role played by lactate as a source of energy and carbon skeletons for the fetal brain during late gestation. Consequently, we investigated the time course of lactate incorporation into $\mathrm{CO}_{2}$, phospholipids, and sterols during the last $3 \mathrm{~d}$ of the gestation. To evaluate the relative importance of lactate as a precursor of brain lipids, the contribution of glucose and 3-hydroxybutyrate as substrates for fetal rat brain lipid synthesis was also investigated.

\section{MATERIALS AND METHODS}

Reagents. L-[U- $\left.{ }^{14} \mathrm{C}\right]$ lactate $(177 \mathrm{Ci} / \mathrm{mol}), \quad \mathrm{D}-\left[6-{ }^{14} \mathrm{C}\right]$ glucose $(55.8 \mathrm{Ci} / \mathrm{mol}), \mathrm{D}-3$-hydroxy $\left[3-{ }^{14} \mathrm{C}\right]$ butyrate $(44.3 \mathrm{Ci} / \mathrm{mol})$, and RS-[2- $\left.{ }^{14} \mathrm{C}\right]$ mevalonolactone $(50.3 \mathrm{Ci} / \mathrm{mol})$ were purchased from New England Nuclear (Boston, MA). L-Lactic acid was obtained from Serva Feinbiochemica (Heidelberg, Germany). D-Glucose and DL-3-hydroxybutyrate were obtained from the Sigma Chemical Co. (St. Louis, MO). Rs- $\left[2-{ }^{14} \mathrm{C}\right]$ mevalonolactone was extemporarily delactonized as described by Popják et al. (10). HPLCgrade solvents were from Scharlau (Barcelona, Spain). Enzymes and coenzymes were obtained from Boëhringer (Mannheim, Germany).

Animals. Albino Wistar rats fed on stock laboratory diet (by wt/vol, carbohydrate $58.7 \%$, protein $17.0 \%$, fat $3.0 \%$, and added salts and vitamins) and of known gestational age were used for the experiments. Virgin females with a weight of 225-250 g were caged overnight with males. Conception was considered to occur at $0100 \mathrm{~h}$ and was confirmed the next morning by the presence of spermatozoa in vaginal smears. Fetuses weighing $2.4 \pm 0.02$, $3.6 \pm 0.03$, or $5.2 \pm 0.1 \mathrm{~g}$ (mean \pm SEM) were delivered on $\mathrm{d}$ $19.5,20.5$, or 21.5 of gestation (21.7 d for full gestation), respectively, by rapid hysterectomy after cervical dislocation of the mother. Newborns were carefully wiped, and their umbilical cords were tied and cut. Newborns were kept in an incubator at $37^{\circ} \mathrm{C}$ in a continuous stream of water-saturated air without feeding.

Incubation of brain slices. After $1 \mathrm{~h}$ of extrauterine life, the newborns were decapitated and the right hemispheres of the forebrain were removed and immediately sliced in a watersaturated cabin. Brain slices (50-70 mg wet weight) were incubated as previously described $(7,11)$. The incubation medium was $2 \mathrm{~mL}$ of PBS (11 mM sodium phosphate, $122 \mathrm{mM} \mathrm{NaCl}$, $3.1 \mathrm{mM} \mathrm{KCl}, 0.4 \mathrm{mM} \mathrm{KH}_{2} \mathrm{PO}_{4}, 1.2 \mathrm{mM} \mathrm{MgSO}_{4}$, and $1.3 \mathrm{mM}$ 
$\left.\mathrm{CaCl}_{2}\right)(12)$ at $\mathrm{pH}$ 7.4. Although the $\mathrm{pH}$ of the medium decreased during incubation to about 7.2 , this is within the physiologic range in the newborn rat (13). The incubation medium contained $2 \mu \mathrm{Ci}$ of L-[U- $\left.{ }^{14} \mathrm{C}\right]$ lactate, $2 \mu \mathrm{Ci}$ of D-[6 $\left.-{ }^{14} \mathrm{C}\right]$ glucose, $1 \mu \mathrm{Ci}$ of D3 -hydroxy $\left[3-{ }^{-14} \mathrm{C}\right]$ butyrate or $1 \mu \mathrm{Ci}$ of RS- $\left[2-{ }^{14} \mathrm{C}\right]$ mevalonate, and $12.0 \mathrm{mM}, 5.4 \mathrm{mM}, 1.0 \mathrm{mM}$, or $10 \mu \mathrm{M}$ of the unlabeled substrates, respectively. The concentrations of L-lactate, $\mathrm{D}$-glucose, and D3-hydroxybutyrate used in the experiments are close to the physiologic blood concentrations in the rat at this stage of the development (2), and they have been shown to be suitable in brain slices (7) and isolated brain cells (8). The concentration of $\mathrm{R}$-mevalonate used was chosen within the range of its linear utilization (results not shown). The flasks were gassed for $30 \mathrm{~s}$ with pure $\mathrm{O}_{2}$ (this was enough to maintain high $\mathrm{PO}_{2}$ in the incubation medium throughout the experiment), sealed with rubber caps, and incubated in a shaking water-bath at $37^{\circ} \mathrm{C}$. Incubations were stopped after $2 \mathrm{~h}$ by injection of $0.2 \mathrm{~mL}$ of $4.75 \mathrm{M} \mathrm{HClO}_{4}$ through the rubber cap into the main well. Shaking was continued for an additional $20 \mathrm{~min}$ to facilitate the trapping of $\mathrm{CO}_{2}$. The ${ }^{14} \mathrm{CO}_{2}$ was trapped by $3.56 \mathrm{M} \mathrm{KOH}$ placed in the central well and was measured with a liquid-scintillation counter (LS 1800-Beckman, Beckman Instruments, Inc., Palo Alto, CA). Blanks without slices were carried out in parallel to measure background radioactivity, which was subtracted from the sample values. Preliminary experiments have shown that, under our experimental conditions, the ${ }^{14} \mathrm{CO}_{2}$ evoked was proportional to the weight of tissue in the range of $40-100 \mathrm{mg} /$ flask and was linear over $2 \mathrm{~h}$ (11). The width of the slice (approximately $0.5 \mathrm{~mm}$ ) has been shown to be sufficiently thin to allow an adequate oxygenation of the brain cells (14).

Extraction of total lipids. At the end of the incubation, the slices were frozen under liquid nitrogen. Total lipids were extracted from the powdered tissue with $2 \mathrm{~mL}$ of a mixture of chloroform:methanol $(2: 1, \mathrm{vol} / \mathrm{vol})$ as in the method described by Folch et al. (15) for $16 \mathrm{~h}$ at $-20^{\circ} \mathrm{C}$. The extract was washed twice with $0.8 \mathrm{~mL}$ of $0.3 \%$ (wt/vol) $\mathrm{NaCl}$ saturated with chloroform. The organic phase was divided into two aliquots; $0.1 \mathrm{~mL}$ was used for the measurement of the radioactivity incorporated into total lipids, and $1.0 \mathrm{~mL}$ was gently dried under a stream of $\mathrm{N}_{2}$ and kept at $-20^{\circ} \mathrm{C}$ until subjected to phospholipid separation by HPLC.

Extraction of nonsaponifiables. Nonsaponifiable material (mainly sterols) was extracted essentially as described by Edmond and Popják (16): brain slices were saponified at $70^{\circ} \mathrm{C}$ with $4 \mathrm{~mL}$ of $53.5 \mathrm{M} \mathrm{KOH}$ :ethanol $(1: 1, \mathrm{vol} / \mathrm{vol})$ for $2 \mathrm{~h}$; unsaponifiable material was extracted three times with $5 \mathrm{~mL}$ of petroleum ether $\left(40-60^{\circ} \mathrm{C}\right)$, and the combined petroleum extracts were concentrated to dryness with a stream of $\mathrm{N}_{2}$. The extract was kept at $-20^{\circ} \mathrm{C}$ until subjected to separation by HPLC.

Separation of phospholipids by HPLC. Phospholipid species were separated by an HPLC isocratic method, essentially as described by Kaduce et al. (17), using a liquid chromatography pump system (114 M-Beckman, Beckman) on a normal-phase column of silica $(4.6 \mathrm{~mm} \times 25 \mathrm{~cm}$, with a $5-\mu \mathrm{m}$-diameter silica particle, Ultrasphere, Beckman). The eluent was acetonitrile:methanol:9.79 $\mathrm{M} \mathrm{H}_{2} \mathrm{SO}_{4}(100: 3: 0.052, \mathrm{vol} / \mathrm{vol} / \mathrm{vol})$ at a flow rate of $1 \mathrm{~mL} / \mathrm{min}$ and a pressure of $600 \mathrm{psi}$. The dried lipid extracts were redissolved in $30 \mu \mathrm{L}$ of chloroform:methanol (2:1, $\mathrm{vol} / \mathrm{vol}$ ) and injected into the column. Elution was monitored at a wavelength of $205 \mathrm{~nm}$ (163-Beckman). Signals were channeled to an electronic integrator (SP 4293, Spectra Physics, San José, $\mathrm{CA}$ ), and the retention times of PI (5.6), PS (7.8), PE (9.2), PC (12.6), and sphingomyelin (21.5) were identified by the comparison with commercial standards (purity: $\geq 97 \%$, Sigma). Eluates $(0.5-\mathrm{mL}$ fractions) were collected into scintillation vials using a fraction collector (model 2110, Bio-Rad, Richmond, CA) coupled to the detector output, and the radioactivity was counted. A typical chromatogram of the lipid extract is shown in Figure $1 a$. Figure $1 b$ shows a typical distribution of radioactivity from $\mathrm{L}-\left[\mathrm{U}_{-}{ }^{14} \mathrm{C}\right]$ lactate among the lipids. The recovery of the radioac-

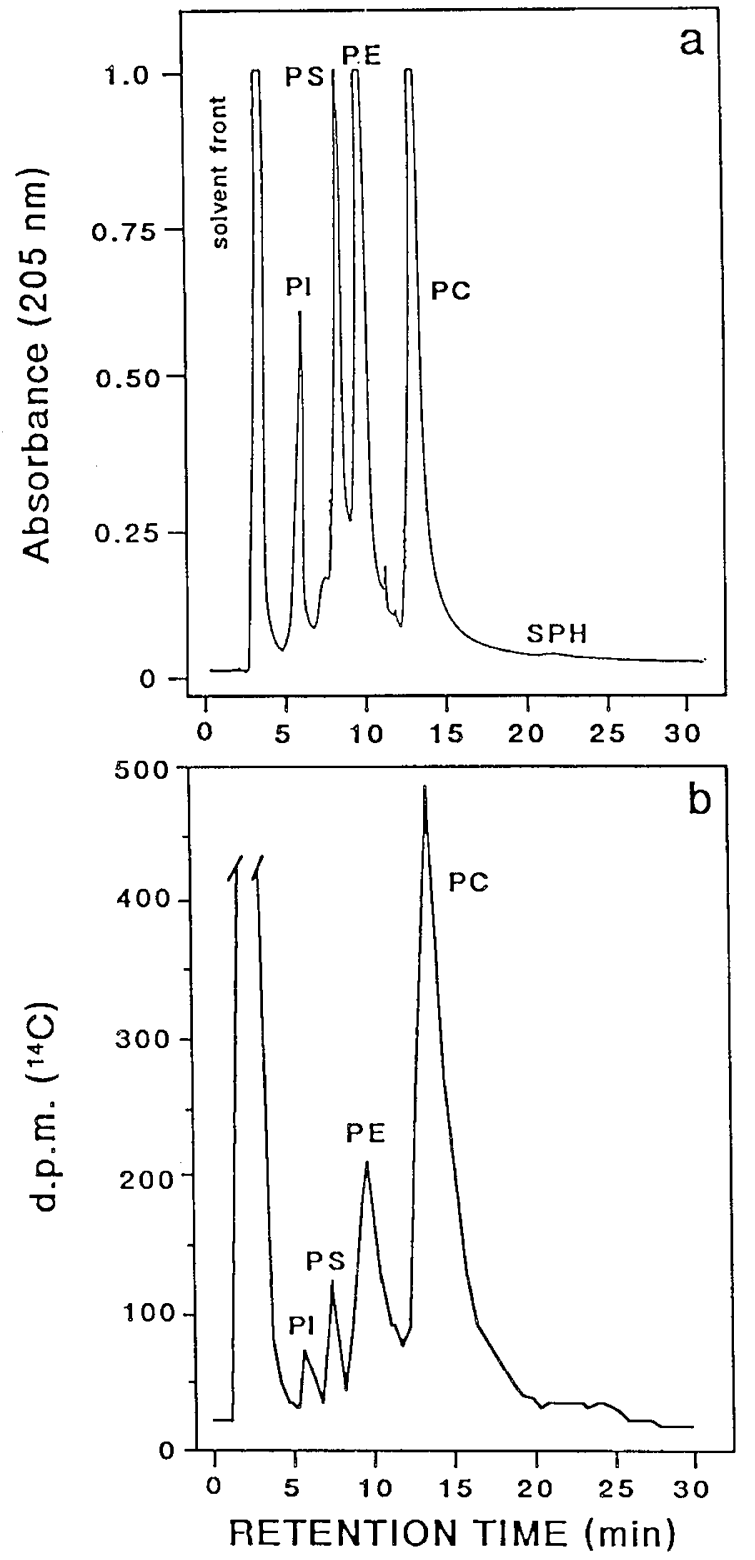

Fig. 1. Isocratic separation by HPLC of fetal brain phospholipids. The brain total lipid extract was injected in a normal-phase column of silica with a eluent mixture of acetonitrile:methanol:9.79 $\mathrm{M} \mathrm{H}_{2} \mathrm{SO}_{4}$ (100:3:0.052, vol/vol/vol) at a flow rate of $1 \mathrm{~mL} / \mathrm{min}$. a, Typical HPLC chromatogram of the fetal brain lipid extract; $b$, typical distribution of ${ }^{14} \mathrm{C}$ from L-[U- $\left.{ }^{14} \mathrm{C}\right]$ lactate among the lipids. $S P H$, sphingomyelin.

tivity was $85-95 \%$. A fraction eluted together with the solvent front contained sterols and sterol esters, which was verified by thin layer chromatography (Silicagel G-200, Merck, Darmstad, Germany) using a system of chloroform:acetone (95:5, vol/vol) as the mobile phase. The radioactivity incorporated into sphyngomyelin was always undetectable.

Separation of nonsaponifiables by HPLC. Nonsaponifiable species were separated by an HPLC isocratic method using a reversed-phase column of silica- $C_{18}(4.6 \mathrm{~mm} \times 25 \mathrm{~cm}, 5-\mu \mathrm{m}$ particle diameter, Ultrasphere-ODS, Beckman) with acetonitrile:methanol $(10: 1, \mathrm{vol} / \mathrm{vol})$ as eluent and a flow rate of $1 \mathrm{~mL} /$ min and a pressure of 700 psi. The dried nonsaponifiable lipid extracts were redissolved in $30 \mu \mathrm{L}$ of chloroform and injected into the column. Elution was monitored at a wavelength of 205 $\mathrm{nm}$. Signals were channeled to an integrator, and the retention times of desmosterol (30.8 and 34.0), lanosterol (42.5 and 46.6), cholesterol (53.8), and squalene (62.5) were identified by the comparison with commercial standards (purity: $\geq 97 \%$, Sigma). 
Eluates $(0.5-\mathrm{mL}$ fractions) were collected into scintillation vials and the radioactivity counted. A typical chromatogram of the nonsaponifiable extract with lanosterol and squalene as internal standards is shown in Figure $2 a$. Figure $2 b$ shows a typical distribution of radioactivity from $\mathrm{L}-\left[\mathrm{U}-{ }^{14} \mathrm{C}\right]$ lactate among the nonsaponifiable species. The recovery of the radioactivity was $70-80 \%$.

Analytical procedures. D-3-Hydroxybutyrate was determined as described by Williamson and Mellanby (18), D-glucose as Bergmeyer et al. (19), and L-lactate as Gutmann and Wahlefeld (20). The specific radioactivity of the substrates found in the blanks was used for the calculations. The rates of substrate utilization by the brain slices were expressed as $\mu \mathrm{mol}$ (or nmol) of L-lactate, D-glucose, D-3-hydroxybutyrate, or R-mevalonate incorporated into $\mathrm{CO}_{2}$, total lipids, phospholipids, or nonsapon-
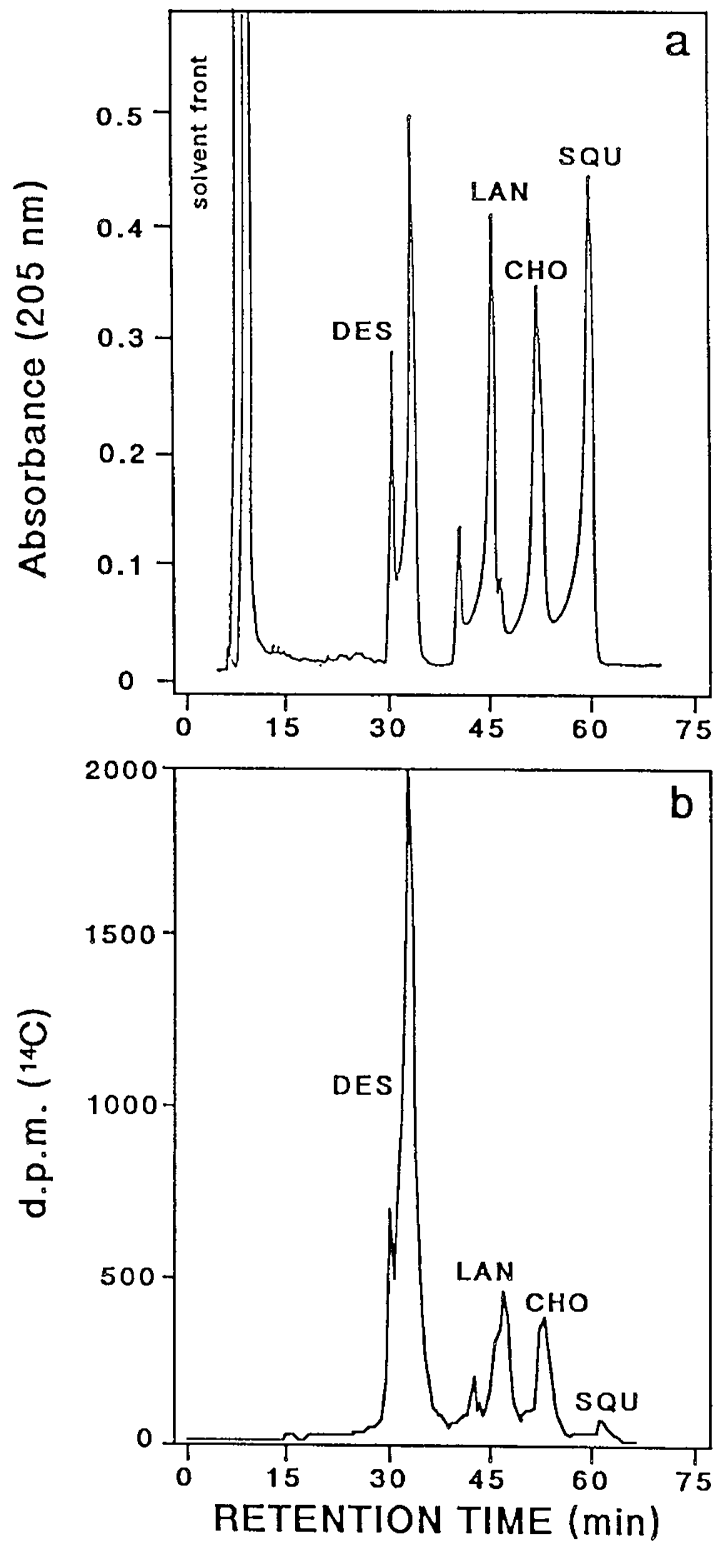

Fig. 2. Isocratic separation by HPLC of fetal brain nonsaponifiables. The brain nonsaponifiable lipid fraction containing lanosterol and squalene as internal standards was injected in a reversed-phase column of silica- $\mathrm{C}_{18}$ with an eluent mixture of acetonitrile:methanol (10:1, vol/vol) at a flow rate of $1 \mathrm{~mL} / \mathrm{min}$. $a$, Typical HPLC chromatogram of the fetal brain nonsaponifiable extract containing lanosterol and squalene as internal standards; $b$, typical distribution of ${ }^{14} \mathrm{C}$ from $\mathrm{L}-\left[\mathrm{U}-{ }^{14} \mathrm{C}\right]$ lactate among the nonsaponifiable species. $D E S$, desmosterol; $L A N$, lanosterol; $C H O$, cholesterol, and $S Q U$, squalene. ifiables $/ \mathrm{h} / \mathrm{g}$ wet weight. Results are means \pm SEM. Statistically significant differences were tested by an analysis of variance.

\section{RESULTS}

Substrate utilization by fetal brain during late gestation. Table 1 shows the rate of incorporation of lactate, glucose, and 3hydroxybutyrate in $\mathrm{CO}_{2}$ or lipids in fetal brain slices during the last $3 \mathrm{~d}$ of gestation. The rate of oxidation and lipogenesis from lactate showed no changes during these last $3 \mathrm{~d}$. However, glucose utilization markedly decreased during the period studied. Thus, the rate of oxidation decreased by about 10 and $22 \%$ on the penultimate and on the last day of gestation, respectively; lipogenesis decreased by about 18 and $22 \%$ on the penultimate and on the last $\mathrm{d}$ of the gestation, respectively (Table 1). 3-Hydroxybutyrate utilization showed a pattern similar to that found for glucose. 3-Hydroxybutyrate oxidation decreased by about 15 and $33 \%$ on the penultimate and on the last day of the gestation, respectively; lipogenesis decreased by about 14 and $20 \%$ on the penultimate and on the last day of the gestation, respectively (Table 1).

The rate of lactate oxidation was the highest found for the three substrates assayed. Thus, lactate oxidation was 7.5 -fold higher than glucose at $19.5 \mathrm{~d}$, and this difference increased to 9.8 -fold at 21.5 d of gestation. Similarly, lactate oxidation was 2.8-fold higher than 3-hydroxybutyrate at $19.5 \mathrm{~d}$ and increased to 4.7 -fold at $21.5 \mathrm{~d}$ of gestation (Table 1). The rate of lipogenesis from lactate was also the highest found for the three substrates assayed. Thus, lipogenesis from lactate was 1.2-fold higher than glucose and this difference increased to 1.8 -fold at $21.5 \mathrm{~d}$ of gestation. Similarly, lipogenesis from lactate was 5.2-fold higher than 3-hydroxybutyrate at $19.5 \mathrm{~d}$ and increased to 7.4 -fold at $21.5 \mathrm{~d}$ of gestation (Table 1).

Rate of substrate incorporation into phospholipid species in fetal brain during late gestation. Table 2 shows the incorporation of lactate, glucose, and 3-hydroxybutyrate into phospholipid species. Brain phospholipids were separated by HPLC, and the radioactivity incorporated in each phospholipid fraction was measured by liquid scintillation counting. PC was the main phospholipid synthesized from lactate, glucose, and 3-hydroxybutyrate, accounting for about $75 \%$ of the rate of total phospholipid synthesis (Table 2). PC synthesis from lactate slightly decreased during the last day of the gestation, but its synthesis from glucose and 3-hydroxybutyrate decreased markedly throughout the observation period (Table 2). The rate of PE synthesis was $15-20 \%$ of the rate of total phospholipid synthesis in these circumstances. PE synthesis from lactate decreased on the last day of the gestation, but its synthesis from glucose and 3hydroxybutyrate decreased markedly throughout the $3 \mathrm{~d}$ studied (Table 2). The rate of PS synthesis from lactate increased during the last day of gestation, although that from glucose was not modified and that from 3-hydroxybutyrate decreased throughout the period studied (Table 2). It should be noted that the ratio of $\mathrm{PE} / \mathrm{PS}$ synthesis was about 2.5 at $21.5 \mathrm{~d}$ of gestation, but this ratio was 1.1 from 3-hydroxybutyrate (Table 2). The rate of PI synthesis was about $1.4-3.4 \%$ of the rate of total phospholipid synthesis from lactate and glucose and about $8 \%$ of that from 3hydroxybutyrate (Table 2). During the last $3 \mathrm{~d}$ of gestation, total phospholipid synthesis from lactate, glucose, and 3-hydroxybutyrate decreased by 23,42 , and $66 \%$, respectively.

Rate of substrate incorporation into nonsaponifiable species in fetal brain during late gestation. Table 3 shows the rates of lactate, glucose, 3-hydroxybutyrate, and mevalonate incorporation into fetal brain sterols during late gestation. Squalene accounted for $1-2 \%$ of the rate of total nonsaponifiables synthesis from lactate, glucose, and 3-hydroxybutyrate. The rates of lanosterol and cholesterol syntheses were similar, each accounting for $20 \%$ of the rate of total nonsaponifiables synthesis. The rate of desmosterol synthesis from all the substrates assayed was the highest observed (Table 3), accounting for about $62 \%$ of the rate 
Table 1. Rate of lactate, glucose, and 3-hydroxybutyrate utilization to $\mathrm{CO}_{2}$ and total lipids in fetal brain during late gestation*

\begin{tabular}{ccccc}
\hline & \multirow{3}{*}{$\begin{array}{c}\text { Gestational } \\
\text { period }(\mathrm{d})\end{array}$} & \multicolumn{3}{c}{ Substrate $(\mu \mathrm{mol})$ incorporated/h/g wet wt } \\
\cline { 3 - 5 } & 19.5 & Lactate & Glucose & 3-Hydroxybutyrate \\
\hline Oxidation & 20.5 & $4.50 \pm 0.35$ & $0.611 \pm 0.025$ & $1.57 \pm 0.09$ \\
& 21.5 & $4.29 \pm 0.51$ & $0.549 \pm 0.005 \dagger$ & $1.34 \pm 0.07 \dagger$ \\
Lipogenesis & 19.5 & $4.22 \pm 0.13$ & $0.428 \pm 0.014 \ddagger$ & $0.90 \pm 0.06 \ddagger$ \\
& 20.5 & $1.51 \pm 0.10$ & $1.29 \pm 0.07$ & $0.29 \pm 0.02$ \\
& 21.5 & $1.38 \pm 0.08$ & $1.06 \pm 0.1 \dagger$ & $0.25 \pm 0.01 \dagger$ \\
& $1.48 \pm 0.07$ & $0.83 \pm 0.03 \dagger$ & $0.20 \pm 0.01 \dagger$ \\
\hline
\end{tabular}

* Fetal rat brain slices were incubated at $37^{\circ} \mathrm{C}$ in $\mathrm{PBS}(\mathrm{pH} 7.4)$ containing the ${ }^{14} \mathrm{C}$-labeled substrates. Oxidation was determined from the measured ${ }^{14} \mathrm{CO}_{2}$ evoked by the slice. Lipogenesis was determined from the total lipid fraction extracted with chloroform:methanol (2:1, vol/vol) as described in Materials and Methods. Results are means \pm SEM for seven to ten fetuses from three to six different litters.

$\dagger p<0.05$ compared with previous gestational day.

$\ddagger p<0.001$ compared with previous gestational day.

Table 2. Incorporation of lactate, glucose, and 3-hydroxybutyrate into phospholipid species in fetal brain during late gestation*

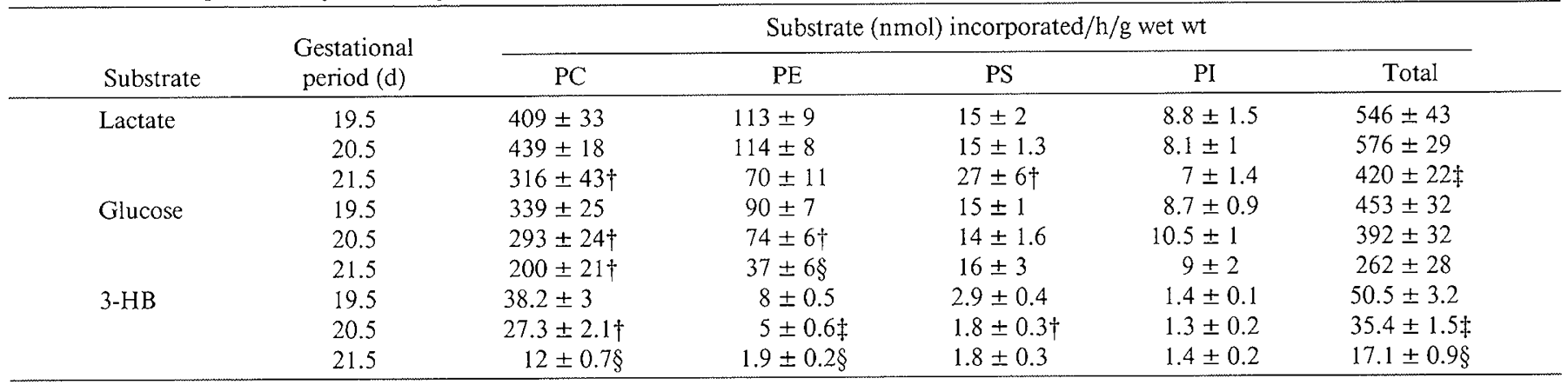

* Fetal rat brain slices were incubated at $37^{\circ} \mathrm{C}$ in PBS (pH 7.4) containing the ${ }^{14} \mathrm{C}$-labeled substrates. Lipids were extracted with chloroform:methanol $(2: 1, \mathrm{vol} / \mathrm{vol})$ and separated by HPLC as described in Materials and Methods. Results are means \pm SEM for six to seven fetuses from three to five different litters. 3-HB, 3-hydroxybutyrate.

$\dagger p<0.05$ compared with previous gestational day.

$\ddagger p<0.01$ compared with previous gestational day.

$\S p<0.001$ compared with previous gestational day.

Table 3. Incorporation of lactate, glucose, 3-hydroxybutyrate, and mevalonate into nonsaponifiables in fetal brain during late gestation*

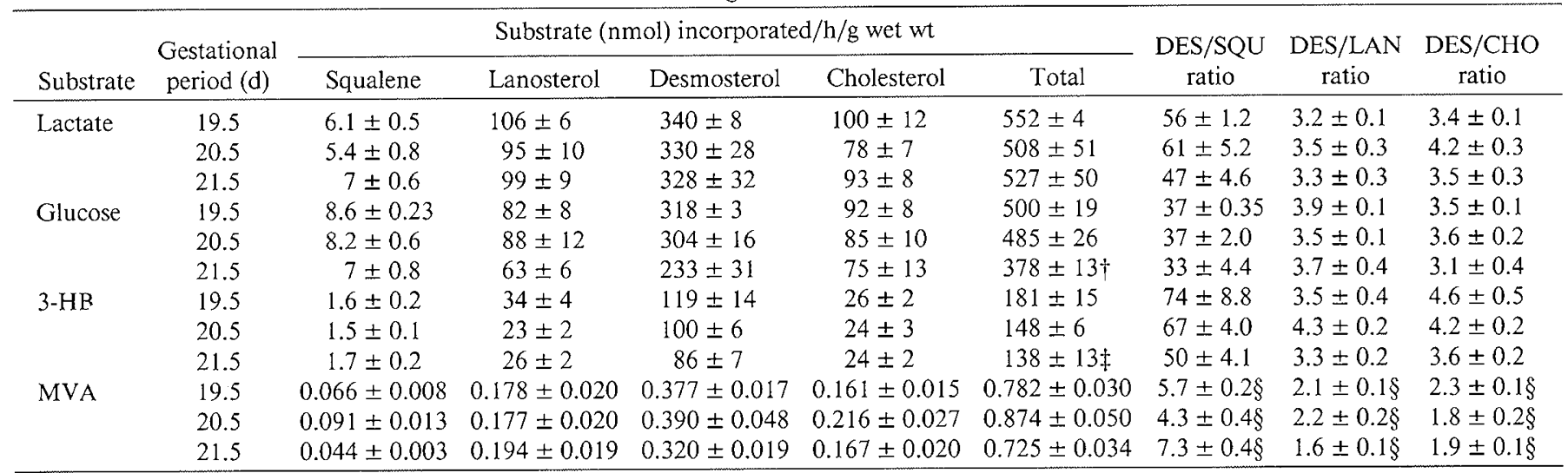

* Fetal rat brain slices were incubated at $37^{\circ} \mathrm{C}$ in PBS ( $\mathrm{pH} 7.4$ ) containing the ${ }^{14} \mathrm{C}$-labeled substrates. The extraction and separation by $\mathrm{HPLC}$ of the nonsaponifiable species were carried out as described in Materials and Methods. Results are means \pm SEM for five to six fetuses from three to four different litters. DES, desmosterol; SQU, squalene; LAN, lanosterol: CHO, cholesterol; 3-HB, 3-hydroxybutyrate; and MVA, R-mevalonate.

$\dagger p<0.05$ compared with 19.5 and $20.5 \mathrm{~d}$.

$\ddagger p<0.05$ compared with $19.5 \mathrm{~d}$.

$\S p<0.001$ compared with lactate, glucose, and 3-hydroxybutyrate on the same gestational day.

of total nonsaponifiables synthesis. When the intermediate of the cholesterol synthesis, mevalonate, was assayed as a substrate, desmosterol only accounted for $44 \%$ of the rate of total nonsaponifiables synthesis, and the proportion of lanosterol and cholesterol syntheses increased to about $25 \%$. No significant changes in the time course of sterol synthesis during late gestation were observed (Table 3 ). It should be noted that the ratios of desmosterol/squalene, desmosterol/lanosterol, and desmosterol/choles- terol syntheses were significantly lower with mevalonate as substrate as compared with lactate, glucose, and 3-hydroxybutyrate at all the gestational periods studied (Table 3 ).

\section{DISCUSSION}

The importance of lactate as an alternative fuel for the brain during the early postnatal period has been reported previously 
$(21,22)$. In this sense, it has been shown that lactate is an important substrate for the brain, because it is preferred to glucose or 3-hydroxybutyrate as an energetic and lipogenic precursor immediately after delivery in the rat $(7,8)$. The results shown in Table 1 suggest that lactate is also an important metabolic substrate for the fetal brain during late gestation. Thus, during the last $3 \mathrm{~d}$ of the gestation, fetal rat brain oxidates lactate at a higher rate than those observed for glucose or 3-hydroxybutyrate. In addition, lactate is incorporated into fetal brain phospholipids and sterols to a greater extent than glucose and 3hydroxybutyrate throughout the last $3 \mathrm{~d}$ of the gestation (Tables 2 and 3 ). Because the development of the brain occurs during late gestation and early neonatal life in the rat (23), the proliferation and differentiation of brain cells takes place during an active period in which striking changes occur in the availability of the main metabolic fuels (2). Because lactate is available during the perinatal period in the rat $(2,3,6,22)$ and is actively utilized by the brain throughout this period (Table 1-3), it can be suggested that lactate plays a relevant role in brain energy homeostasis during development. In the present study, the rate of lactate utilization remained high during the last day of gestation, whereas the rates of glucose or 3-hydroxybutyrate utilization decreased (Table 1), suggesting that lactate may be the main substrate utilized by the brain around birth. It should be noted that lactate may also support part of the energy requirements during the suckling period, as has been reported for rat $(14,24)$, mouse (25), and dog brain (26), because this substrate was preferred to glucose during hypoxia and recovery (21) and during hypoglycemia $(25,26)$.

Similar patterns in the incorporation of glucose into $\mathrm{CO}_{2}$, phospholipids, or sterols during the late fetal period were observed (Tables 1 and 2), which suggests that a common step is limiting glucose utilization by the tricarboxylic acid cycle and lipogenesis. It is thus tempting to speculate that a putative decrease in pyruvate dehydrogenase (EC 1.2.4.1) may be responsible for the decrease in glucose utilization during the last $3 \mathrm{~d}$ of gestation. However, lactate oxidation did not decrease in the same circumstances (Table 1), suggesting that the decrease in the flux through some glycolytic step rather than through pyruvate dehydrogenase may be responsible for blunting glucose utilization by the fetal brain during late gestation. In agreement with this, hexokinase (EC 2.7.1.1) has been shown to be the ratelimiting step for glucose utilization by perinatal brain (27). Whether a putative decrease in the activity of hexokinase is responsible for the decrease of glucose utilization observed in our experiments remains to be elucidated.

3-Hydroxybutyrate was preferentially incorporated into sterols rather than phospholipids, as compared with lactate and glucose (Tables 2 and 3). This is not unexpected, because acetoacetate can be incorporated directly into sterols, unlike fatty acids, where acetoacetate must necessarily be cleaved into acetyl-CoA (28). The decrease in the rate of 3-hydroxybutyrate utilization by fetal brain during late gestation showed a similar pattern concerning the rate of oxidation, phospholipid, or sterol syntheses (Tables $1-3$ ), suggesting that a putative decrease in 3-hydroxybutyrate transport through the plasma membrane may be responsible for the observed decrease of 3-hydroxybutyrate utilization. In this sense, Tildon and Roeder (29) have suggested that the activity of the plasma membrane carrier limits 3-hydroxybutyrate utilization by brain cells. In fact, the Km of this carrier for 3-hydroxybutyrate is very high $(1-2 \mathrm{mM})(29)$, a fact that might suggest that 3-hydroxybutyrate utilization is limited by the activity of the plasma membrane carrier under these circumstances. However, this carrier is shared by lactate (30), whose rate of utilization was not decreased in the same circumstances (Table 1). Consequently, the activity of the plasma membrane monocarboxylate carrier may not be responsible for the decrease in 3-hydroxybutyrate utilization observed during late gestation. On the other hand, 3-hydroxybutyrate utilization may be limited by the activ- ity of 3-hydroxybutyrate dehydrogenase (EC 1.1.1.30) (8), which is very low during the perinatal period $(31,32)$.

The high activity of lactate dehydrogenase $(1.1 .1 .27)$ in fetal brain during late gestation, which is 10 -fold greater than that of hexokinase (33) and 1000-fold greater than that of 3-hydroxybutyrate dehydrogenase $(32,33)$, could explain the high rate of lactate utilization found as compared with glucose or 3-hydroxybutyrate (Table 1). Actually, lactate utilization in perinatal rat brain may be limited by lactate transport across the plasma membrane because the $\mathrm{Km}$ of lactate and 3-hydroxybutyrate utilization coincide in isolated neonatal brain cells (8), probably due to the fact that both substrates share a common monocarboxylate carrier $(30)$.

PC and PE were the phospholipids most actively synthesized from all three substrates assayed, probably because the cytidine pathway $(34,35)$ is already functional in fetal rat brain after 19 $\mathrm{d}$ of gestation (36). In addition, PC and PE syntheses decreased during the last $3 \mathrm{~d}$ of the gestation, although PS and PI syntheses were unchanged or decreased (Table 2). Consequently, it may be suggested that $\mathrm{PC}$ and $\mathrm{PE}$ syntheses are limited by the activity of the cytidine pathway, which presumably decreases during late gestation, unlike the exchange pathway, which remains unchanged under these circumstances (Table 2). The fact that PS synthesis, unlike PC and PE, was not decreased (Table 2), may also be due to the occurrence of a direct pathway in which serine is directly incorporated into PS, as has been recently reported in cultured glioma cells (37). The changes in the phospholipid synthesis observed in our experiments are probably responsible for the changes in brain membrane phospholipid composition occurring around birth. Thus, it has been suggested that PC is important in the regulation of oligodendroglial differentiation, particularly because it lowers membrane fluidity (38). Similarly, brain PS synthesis, which decreased from 3-hydroxybutyrate, was maintained from glucose and even increased from lactate during late gestation (Table 2), may play a physiologic role because phospholipids containing serine participate in a variety of intracellular brain functions, such as in supporting the activity of some membrane-bound enzymes (39) together with some physical membrane properties (34).

The decreased ratios of desmosterol/squalene and desmosterol/lanosterol syntheses observed from mevalonate as substrate, as compared with those from lactate, glucose, or 3-hydroxybutyrate (Table 3), seem to suggest the occurrence of a common step limiting sterol synthesis from lactate, glucose, and 3-hydroxybutyrate, which is avoided by mevalonate. Because lactate, glucose, and 3-hydroxybutyrate share a common pathway from acetyl-CoA, it may be suggested that some step between acetyl-CoA and mevalonate may be limiting the sterol synthesis during late gestation. Because of the low activity of brain 3 hydroxy-3-methylglutaryl-CoA reductase (EC 1.1.1.34) during this period (40), it is tempting to speculate that the rate of sterol synthesis in perinatal brain is controlled by the flux through the 3-hydroxy-3-methyl-glutaryl-CoA reductase catalyzed reaction.

During the neonatal period, high concentrations of desmosterol are found in rodent $(41,42)$ and human brain (43). Our results show that desmosterol is indeed actively synthesized in fetal brain during the perinatal period (Table 3). This is in agreement with the pattern of desmosterol/cholesterol ratio found during brain development (42). The increased synthesis of desmosterol as compared with that of cholesterol could be a result of the decrease in the activity of sterol $\Delta^{24}$-reductase, which has been reported as a rate-limiting step in cholesterol synthesis (44). The preferential synthesis of desmosterol in fetal brain during late gestation is intriguing. However, it is tempting to speculate that the preservation of the double bond in the aliphatic chain of the sterol may be important for conferring brain membranes with those properties that are especially required during the early stages of brain development.

In conclusion, our results suggest that lactate is the main metabolic substrate for the brain during late gestation as com- 
pared with glucose or 3-hydroxybutyrate. The rate of lactate utilization remained high during late gestation, but the rates of glucose and 3-hydroxybutyrate utilization significantly decreased. These results seem to suggest that fetal brain reaches its full capacity for lactate utilization during late gestation, foreseeing that lactate will be the main metabolic substrate during the immediate postnatal period.

Acknowledgments. The authors thank Dr. E. Fernández for his useful discussions, A. Almeida for her kind help with the experiments, and J. Villoria for his technical assistance.

\section{REFERENCES}

1. Robinson AM, Williamson DH 1980 Physiological roles of ketone bodies as substrates and signals in mammalian tissues. Physiol Rev 60:143-187

2. Girard JR, Cuendet GS, Marliss EB, Kervran A, Rieutort M, Assan R 1973 Fuels, hormones and liver metabolism at term during the early postnatal period in the rat. J Clin Invest 53:3190-3200

3. Fernández E, Valcarce C, Cuezva JM, Medina JM 1983 Postnatal hypoglycaemia and gluconeogenesis in the newborn rat. Delayed onset of gluconeogenesis in prematurely delivered newborns. Biochem J 214:525-532

4. Cuezva JM, Moreno FJ, Medina JM, Mayor F 1980 Prematurity in the rat. I. Fuels and gluconeogenic enzymes. Biol Neonate 37:88-95

5. Juanes MC, Arizmendi C, Medina JM 1986 Attenuation of postnatal hypoxia in the premature newborn rat by maternal treatment with dexamethasone: its relationship with lung phospholipid content. Biol Neonate 50:337-344

6. Medina JM, Cuezva JM, Mayor F 1980 Non-gluconeogenic fate of lactate during the early neonatal period in the rat. FEBS Lett 114:132-134

7. Fernández E, Medina JM 1986 Lactate utilization by the neonatal rat brain in vitro. Competition with glucose and 3-hydroxybutyrate. Biochem J 234:489492

8. Vicario C, Arizmendi C, Malloch G, Clark JB, Medina JM 1991 Lactate utilization by isolated cells from early neonatal rat brain. J Neurochem 57:1700-1707

9. Girard JR, Ferré P, Gilbert M, Kervran A, Assan R, Marliss EB 1977 Fetal metabolic response to maternal fasting in the rat. Am $J$ Physiol 1:E456E463

10. Popják G, Boehm G, Parker TS, Edmond J, Edwards PA, Fogelman AM 1979 Determination of mevalonate in blood plasma in man and rat. Mevalonate "tolerance" tests in man. J Lipid Res 20:716-728

11. Arizmendi C, Medina JM 1983 Lactate as an oxidizable substrate for rat brain in vitro during perinatal period. Biochem $\mathrm{J}$ 214:633-635

12. Elliott KAC 1969 The use of brain slices. In: Lajtha A (ed) Handbook of Neurochemistry, Vol 2. Plenum Press, New York, pp 103-114

13. Vicario C, Juanes MC, Martín-Barrientos J, Medina J 1990 Effect of postnatal hypoxia on ammonia metabolism during the early neonatal period in the rat. Biol Neonate 57:119-125

14. Itoh T, Quastel JH 1970 Acetoacetate metabolism in infant and adult rat brain in vitro. Biochem J 116:641-655

15. Folch J, Lees M, Sloane-Stanley GH 1957 A simple method for the isolation and purification of total lipides from animal tissues. J Biol Chem 226:497509

16. Edmond J, Popják G 1974 Transfer of carbons atoms from mevalonate to $n$ fatty acids. J Biol Chem 249:66-71

17. Kaduce TL, Norton KC, Spector AA 1983 A rapid, isocratic method for phospholipid separation by high-performance liquid chromatography. $J$ Lipid Res 24:1398-1403

18. Williamson DH, Mellanby J 1974 D-(-)-3-Hydroxybutyrate. In: Bergmeyer HU (ed) Methods of Enzymatic Analysis, Vol 4. Verlag Chemie GmbH, Weinheim, Germany, pp 1836-1839

19. Bergmeyer HU, Bernt E, Schmidt F, Stork H 1974 D-Glucose. Determination with hexokinase and glucose-6-phosphate dehydrogenase. In: Bergmeyer HU (ed) Methods of Enzymatic Analysis, Vol 3. Verlag Chemie GmbH, Weinheim, Germany, pp 1196-1201

20. Gutmann I, Wahlefeld AW $1974 \mathrm{~L}-(+)$-Lactate. Determination with lactate dehydrogenase and NAD. In: Bergmeyer HU (ed) Methods of Enzymatic Analysis, Vol 3. Verlag Chemie GmbH, Weinheim, Germany, pp 1464 1468

21. Vannucci RC, Duffy TE 1976 Carbohydrate metabolism in fetal and neonatal rat brain during anoxia and recovery. Am J Physiol 230:1269-1275

22. Medina JM 1985 The role of lactate as an energy substrate for the brain during the early neonatal period. Biol Neonate 48:237-244

23. Small RK, Riddle P, Noble M 1987 Evidence for migration of oligodendrocytetype- 2 astrocyte progenitor cells into the developing rat optic nerve. Nature 328:155-157

24. Dombrowski Jr GJ, Swiatek KR, Chao KL 1989 Lactate, 3-hydroxybutyrate and glucose as substrates for the early postnatal rat brain. Neurochem Res 14:667-675

25. Thurston JH, Hauhart RE, Schiro JA 1983 Lactate reverses insulin-induced hypoglycemic stupor in suckling-weanling mice: biochemical correlates in blood, liver, and brain. J Cereb Blood Flow Metab 3:498-506

26. Hellmann J, Vannucci RC, Nardis EE 1982 Blood-brain barrier permeability to lactic acid in the newborn dog: lactate as a cerebral metabolic fuel. Pediatr Res 16:40-44

27. Heidenreich KA, Gilmore PR, Garvey WT 1989 Glucose transport in primary cultured neurons. J Neurosci Res 22:397-407

28. Miziorko HM, Laib FE, Behnke CE 1990 Evidence for substrate channeling in the early steps of cholesterogenesis. J Biol Chem 265:9606-9609

29. Tildon JT, Roeder LM 1988 Transport of 3-hydroxy $\left[3-{ }^{14} \mathrm{C}\right]$ butyrate by dissociated cells from rat brain. Am J Physiol 255:C133-C139

30. Oldendorf WH 1973 Carrier-mediated blood-brain barrier transport of shortchain monocarboxylic organic acids. Am J Physiol 224:1450-1453

31. Page MA, Krebs HA, Williamson DH 1971 Activities of enzymes of ketonebody utilization in rat brain and other tissues of suckling rats. Biochem $J$ 121:49-53

32. Leong SF, Clark JB 1984 Regional enzyme development in rat brain. Enzymes of energy metabolism. Biochem J 218:139-145

33. Leong SF, Clark JB 1984 Regional enzyme development in rat brain. Enzymes associated with glucose utilization. Biochem J 218:131-138

34. Bishop WR 1988 Assembly of phospholipids into cellular membranes: biosynthesis, transmembrane movement and intracellular translocation. Annu Rev Cell Biol 4:579-610

35. Kent C 1990 Regulation of phosphatidylcholine biosynthesis. Prog Lipid Res 29:87-105

36. Carey EM 1982 The biochemistry of fetal brain development and myelination. In: Jones CT (ed) Biochemical Development of the Fetus and Neonate. Elsevier Biomedical Press, Amsterdam, pp 287-336

37. Xu Z, Byers DM, Palmer SC, Spence MW, Cook HW 1991 Serine utilization as a precursor of phosphatidylserine and alkenyl-(plasmenyl)-, alkyl-, and acylethanolamine phosphoglycerides in cultured glioma cells. J Biol Chem 266:2143-2150

38. Volpe JJ, limore Y, Haven GG, Goldberg RI 1986 Relation of cellular phospholipid composition to oligodendroglial differentiation in C-6 glial cells. J Neurochem 46:475-482

39. Edelman AM, Blumenthal DK, Krebs EG 1987 Protein serine/threonine kinases. Annu Rev Biochem 56:567-613

40. Aragón MC, Giménez Z, Valdivieso F, Mayor F 1978 HydroxymethylglutarylCoA reductase (NADPH) activity in rat brain during development. J Neurochem 30:649-650

41. Kritchevsky D, Holmes WL 1962 Occurrence of desmosterol in developing rat brain. Biochem Biophys Res Commun 7:128-131

42. Bourre JM, Clement M Gerard D, Legrand R, Chaudiere J 1990 Precursors for cholesterol synthesis (7-dehydrocholesterol, 7-dehydrodesmosterol and desmosterol): cholesterol/7-dehydrocholesterol ratio as an index of development and aging in PNS but not in CNS. J Neurochem 54:1196-1199

43. Fumagalli R, Paoletti R 1963 The identification and significance of desmosterol in the developing human and animal brain. Life Sci 5:291-295

44. Hinse $\mathrm{CH}$, Shah SN 1971 The desmosterol reductase activity of rat brain during development. J Neurochem 18:1989-1998 